\title{
EFFECTIVENESS OF DEMONSTRATION METHOD TO TEACH THE ABSTRACT CONCEPTS TO THE CHILdREN BETWEEN THE AgE OF SIX TO TEN. AN EXPERIMENTAL RESEARCH
}

\author{
Muhammad Arshad Hussain \\ Punjab School Education Department, Pakistan
}

\begin{abstract}
The demonstration method is an important element in determining the effectiveness of teaching and learning process in the classroom. This research aims to investigate the effect of demonstration method to improve the students' understanding of the abstract concepts. In this study different simple illustrated short stories with moral lessons including honesty, faithfulness, kindness and trustworthiness have been selected and played in ECE (early childhood education) room on LED and repetitive demonstration to convey the abstract concepts associated with emotions including happiness, sadness, love and hatred have been demonstrated by the teacher. This study involved 30 students between the age six to ten of Government Primary School Dhok Ali Khan. The instruments used for data collection were pre-test through observation, record, repetitive demonstration and post-test. The data have been collected in graphs and percentage. In findings, there is a significant increase in positive achievement of the students. The study also helped changed the reaching practices and improved the children's interest in learning different concepts and other activities. This paper deals with how to teach abstract concepts and other activities.
\end{abstract}

\section{KEYWORDS}

Abstract concepts, repetitive demonstration, demonstration method,

\section{INTRODUCTION}

Abstract concepts refer to those concepts which do not have any physical existence. They are tangible. They cannot be touched, seen and measured. For instance, sadness, happiness, honesty and anger etc. Abstract concepts ("Honesty") differ from concrete one ("Dog"), as they do not have a restricted, explicit and perceivable referent. Abstract concepts take their meaning from the emotional system that is involved in online interaction with the world.

Teaching is an art. It is a very challenging profession. It is a myth about the teaching that it is inborn capability and skill of a person but it is wrong. It is a matter of practicing, attention, hard work, passion, determination, consistency and perseverance. As far as level or grade is concerned, it is very difficult to teach the young children. A teacher has to apply all his methods and techniques to teach them different concepts and ideas. It is observed that the younger children can understand the concrete objects or things easily because of their physical existence. As far as the abstract concepts are concerned, the young Children especially between the ages of 6 to 10 are unable to understand the abstract concepts. They only can understand the concepts associated with the emotions like sad, happy, good or bad but they can't understand the abstract concepts other than emotional linked concepts e.g. (Lucid). So, the emotional development of the children is paramount in this regard. 
As there are different methods including GTM, Direct Method. Suggestopedia, Audio lingual method etc. have been implemented according to learning environment and requirement, Demonstration is considered one of the best methods to teach abstract concepts to the younger children upto the age of 10. According to Nuri Ramdhan, Edy Suraya demonstration method increases the students' outcomes in multiplication operation. It indicates that we cannot deny the effectiveness of demonstration method.

A demonstration refers to illustrating a point in a lecture through facial expressions, gestures, postures and body movements. For instance, kinesthetic etc. It involves using something other than routine visual aids or other ways of teaching. According to Gardener (1978) demonstration enables the learner to evoke "wow" experience. As a result, it enhances the students' curiosity and reasoning ability. Furthermore, Gerber, Caballo \& Marek, (2001) say that it can have impact on the students' achievements. The researchers like Hofstein \& Kempa, (1985) think that traditional methods are appreciated by only those students who are in favour of the didactic method of teaching while demonstration method is one of the favourite, interesting and beneficial for the students due its diversity and uniqueness. It is assumed that demonstration method can be fruitful and effective for the students of low cognitive abilities ( Meger et Al 2003; Rade 2009; Baddock \& Bucat, 2008). Demonstration method is the method of exhibiting and demonstrating things, ideas, rules, and sequence etc. It is an activity to engage the learners in the task by concentration and paying heed to them to convey the subject matter to the students. The purpose of using demonstration method is to exhibit the existence of the material to be learned and taught.

It is observed that Grade-5 students undergo difficulties while doing the exercise of abstract concepts due to lack of understanding in that very concepts. They are unable to solve the exercises of abstract concepts. Hence they are lazy and don't take interest to learn the abstract concepts. They only can do those exercises which they have learned from their teacher. They don't have creativity in this regard.

\section{LiterATURE REVIEW}

Demonstration method helps the students to understand the concepts other than abstract. In addition, it helps the students to understand the redox reactions in chemistry. Demonstration method enhances the students' achievement and efficiency to cope with the concepts. If demonstrations are properly incorporated and managed into learning of the concepts, have potential to play an important role in developing deep insight and understanding of the chemical concepts (Ahmad Baaheer, Muhammad Hugerat, Naj Kortam, Avi Hofstein (2016).

It is observed that demonstration method enhance the students' ability to cope with number operation in mathematics through concrete objects. It develops the students' outcome in learning activity at pre cycle, Cycle I and Cycle II to do number operations.

A student can do multiplication operations upto minimum determined criteria. In fact, demonstration method with concrete objects as media, the students can improve their skills because in demonstration method it is mandatory for the students to participate actively in group discussion, find the solutions of the problem faced, and share ideas with friends and teachers. As a result, the reasoning skills, creative and cognitive abilities of the students enhance. Consequently, they can solve the problems with the help of their critical thinking.

According to result of the study, demonstration method builds a relationship between prior knowledge and procedural knowledge. Thus, it helps to fill the gap between prior knowledge and procedural knowledge. As a result, the students gain deep insight and critical thinking that enable them to improve their understanding. In addition, demonstration method with concrete 
objects, the students not only listen and receive the teacher's message but they participate eagerly to dig out the solution of the required issue or problem. Thus, the students' active participation increase their creative, cognitive and critical thinking abilities to improve their learning outcome ( Nuri Ramdhan \& Edy Surya).

James Nisbet (1949) dwells on the nature of the demonstrations. He thinks that it is important to determine or deciding what kind of activities you are going to do e.g. teaching, demonstrating or organizing etc. It is obvious that too demonstrations are effective one to cover too much practical work. Old methods have their own significance and effectiveness and the teacher have to use them to predominate. Demonstrations are essential, but they must be short in duration, and encompass as few steps or units as possible so that the students may remember and use them. Demonstration is as teaching technique to teaching of the bakery confectionery, the vocational aspects of Secondary and Further Education. The said article refers to vocational training especially related to baking in which experience of demonstration have been quoted. According to the researcher demonstration method play vital role in understanding but it must be for short time. The mentioned study indicates that demonstrations are necessary to make the teaching and learning process effective one.

K. Giridharam \& R. Raju (2017) investigated the impact of Teaching Strategies and Impact of Teacher Effect on the students' Academic achievement in engineering education. They adopted two different teaching strategies, Demonstration and Lecturer Strategies. Demonstration Strategy was found to be significantly better than Lecture Strategy.

Saul Mcleod, (2018). (2018) described Theory of Cognitive Development in which he explained Piaget's four stages of a child's cognitive development. These are: 1 . Sensory motor (birth to age 2), 2. Preoperational (from the age 2 to age 7), 3.Concerete operational (from the age 7 to the age 11), 4. Formal operation (age 11+ adolescent and adulthood). Jean Piaget views that a child is able to understand the abstract concepts when he is 11 years old or above, less than 11 years the child can understand the concrete things only but this study's focus is to make the child able to understand the abstract concepts below the age of 11. For this purpose, the researcher adopted a specific method, called demonstration method to deal with that deficiency of the child. In other words, the researcher challenged Jean Piaget's Theory of Cognitive Development.

To sum up: Existing literature indicates that the demonstration method is an effective method in teaching and learning process in any educational setting whether these vocational and scientific or other than vocational and scientific, demonstration method play pragmatic role teaching and learning process.

Gap: The existing literature shows that nobody tried demonstration method to check its effectiveness in teaching abstract concepts to the children between the age six to ten. Therefore, the present study aims to investigate it.

\section{RESEARCH QUESTIONS}

I. How does the demonstration method facilitate teaching and learning process?

II. What is the impact of demonstration method on the students' cognitive ability?

III. How does demonstration method promote the students' level of confidence? 


\section{Methodology}

The researcher used pre-test and post-test method. He conducted the pre-test and post-test in which he observed the students performance in identification of the following abstract concepts.

Table 1

\begin{tabular}{|l|l|l|l|l|}
\hline Honesty & Truthfulness & Kindness & Trustworthiness & Hatred \\
\hline Faithfulness & Happiness & Sadness & Love & \\
\hline
\end{tabular}

After conducting pre-test the researcher started to teach the students through demonstration method. He developed a story for each concept. He linked each concept with a story. For this purpose he used ECE (early childhood education) room of the school in which he played the different animated short stories on LED. The moral lessons of those very stories were honesty, truthfulness, kindness, trustworthiness, faithfulness, happiness, sadness, love and hatred respectively. The researcher played the following stories to demonstrate the said abstract concepts. He taught his students ten days. He demonstrated only one story per day. The duration of the video was between five to ten minutes. After letting them watched the video of the story, they were demonstrated the different aspects of the story to get the students understanding of the required concept.

Table 2

\begin{tabular}{|c|c|}
\hline Story & Moral Lesson \\
\hline An angel and the Axe & Honesty \\
\hline $\begin{array}{l}\text { The robber became good citizens: A well- } \\
\text { known strory of truthfulness of Hazrat } \\
\text { Sheikh Abdul Qadir Jeelani, a reputed } \\
\text { Muslim Sufi and scholar of his time }\end{array}$ & d \\
\hline A beer and two friends & Trustworthiness and faithfulness \\
\hline
\end{tabular}

Beside these stories, the researcher conveyed the abstract concepts linked with emotions of the students through the following similes. 
Table 3

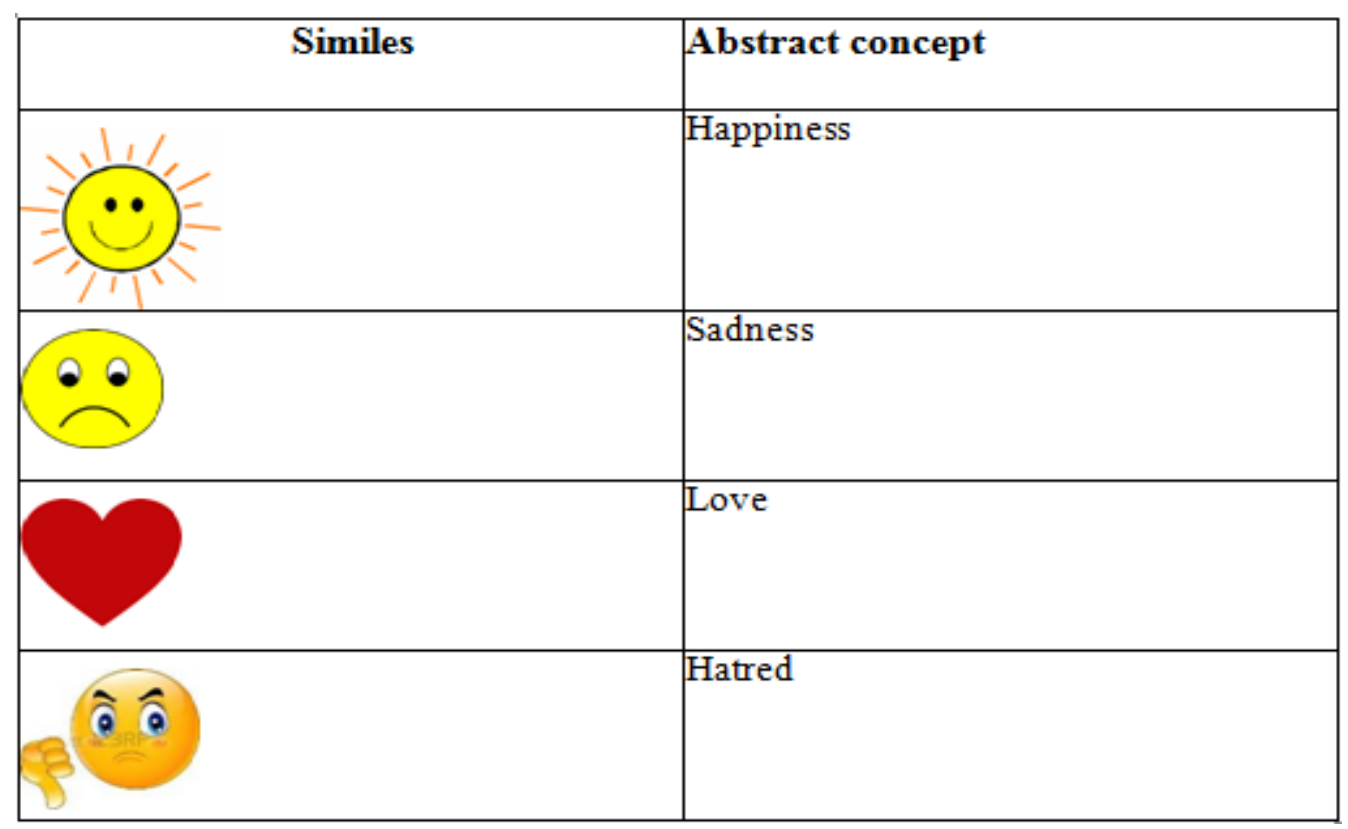

\section{Data Collection}

The instruments used for data collection were pre-test and post-test through observation, record, repetitive demonstration. The data have been collected in numbers and percentage. Pretest and post- test were conducted from thirty students in which they were asked to identify the similes associated with abstract concepts including anger, sadness, happiness, love and hatred. Besides, the students were given understanding of the abstract concepts including honesty, truthfulness, trustworthiness and kindness by playing and demonstrating the stories having the moral lessons e.g. honesty, truthfulness etc. For instance, "A bear and two friends" exhibits trustworthiness and so on.

\subsection{Pre-Test}

The students showed the following result in pre-test.

Table 4

\begin{tabular}{|l|l|l|}
\hline Name & Marks & Percentage \% \\
\hline Azhar & 03 & 30 \\
\hline Bilal & 02 & 20 \\
\hline Asad & 01 & 10 \\
\hline Kaleem & 02 & 20 \\
\hline Jawad & 04 & 40 \\
\hline Malaika & 02 & 20 \\
\hline Nabeela Gul & 04 & 40 \\
\hline Mehvish & 01 & 10 \\
\hline Alishba sadaqt & 02 & 20 \\
\hline Alishba Perveen & 03 & 30 \\
\hline Ikram Sakhi & 0 & 0 \\
\hline
\end{tabular}


International Journal of Education (IJE) Vol.8, No.2, June 2020

\begin{tabular}{|l|l|l|}
\hline Hamza & 0 & 0 \\
\hline Hassan Javed & 02 & 20 \\
\hline Attar Khan & 0 & 0 \\
\hline Umair & 01 & 10 \\
\hline Muneeb & 3 & 30 \\
\hline Kashif & 03 & 30 \\
\hline Asif & 01 & 10 \\
\hline Danish & 04 & 40 \\
\hline Khailda & 03 & 30 \\
\hline Saba & 04 & 40 \\
\hline Wasif Asmat & 0 & 0 \\
\hline Qamar & 0 & 0 \\
\hline Qadeer Ahmad & 02 & 20 \\
\hline Sajjad & 01 & 10 \\
\hline Shafique & 03 & 30 \\
\hline Naseer & 02 & 20 \\
\hline Waqas & 04 & 40 \\
\hline Younas & 03 & 30 \\
\hline
\end{tabular}

\subsection{Post-test}

The students showed the following result in pre-test.

Table 5

\begin{tabular}{|l|l|l|}
\hline Name & Marks & Percentage \% \\
\hline Azhar & 09 & 90 \\
\hline Bilal & 10 & 100 \\
\hline Asad & 10 & 100 \\
\hline Kaleem & 09 & 90 \\
\hline Jawad & 04 & 40 \\
\hline Malaika & 08 & 80 \\
\hline Nabeela Gul & 09 & 90 \\
\hline Mehvish & 10 & 100 \\
\hline Alishba sadaqt & 09 & 90 \\
\hline Alishba Perveen & 07 & 70 \\
\hline Ikram Sakhi & 08 & 80 \\
\hline Hamza & 07 & 70 \\
\hline Hassan Javed & 08 & 80 \\
\hline Attar Khan & 09 & 90 \\
\hline Umair & 10 & 100 \\
\hline Muneeb & 07 & 70 \\
\hline Kashif & 02 & 20 \\
\hline Asif & 08 & 80 \\
\hline Danish & 03 & 30 \\
\hline Khailda & 07 & 70 \\
\hline Saba & 03 & 30 \\
\hline Wasif Asmat & 07 & 70 \\
\hline Qamar & 08 & 80 \\
\hline Qadeer Ahmad & 09 & 90 \\
\hline Sajjad & 07 & 70 \\
\hline & & \\
\hline
\end{tabular}


International Journal of Education (IJE) Vol.8, No.2, June 2020

\begin{tabular}{|l|l|l|}
\hline Shafique & 06 & 60 \\
\hline Naseer & 09 & 90 \\
\hline Waqas & 08 & 80 \\
\hline Younas & 10 & 100 \\
\hline
\end{tabular}

\section{DAta AnAlysis}

The data been analyzed by using data bars to compare pre-test and post-test variables in excel.

Table 6

\begin{tabular}{|l|l|l|}
\hline & & \\
Score Greater than Pre-Test & Score Equal to Pre-Test & Score Less than Pre-Test \\
\hline
\end{tabular}

Table 7

\begin{tabular}{|c|c|c|c|}
\hline Name & Pre-Test & Post-Test & Difference \\
\hline Azhar & 3 & 9 & 6 \\
\hline Bilal & 2 & 10 & 8 \\
\hline Asad & 1 & 10 & 9 \\
\hline Kaleem & 2 & 9 & 7 \\
\hline Jawad & 4 & 4 & 0 \\
\hline Malaika & 2 & 8 & 6 \\
\hline Nabeela Gul & 4 & 9 & 5 \\
\hline Mehvish & 1 & 10 & 9 \\
\hline Alishba sadagt & 2 & 9 & 7 \\
\hline Alishba Perveen & 3 & 7 & 4 \\
\hline Ikram Sakhi & 0 & 8 & 8 \\
\hline Hamza & 0 & 7 & 7 \\
\hline Hassan Javed & 2 & 8 & 6 \\
\hline Attar Khan & 0 & 9 & 9 \\
\hline Umair & 1 & 10 & 9 \\
\hline Muneeb & 3 & 7 & 4 \\
\hline Kashif & 3 & 2 & -1 \\
\hline Asif & 1 & 8 & 7 \\
\hline Danish & 4 & 3 & -1 \\
\hline Khailda & 3 & 7 & 4 \\
\hline Saba & 4 & 3 & -1 \\
\hline Wasif Asmat & 0 & 7 & 7 \\
\hline Qamar & 0 & 8 & 8 \\
\hline Qadeer Ahmad & 2 & 9 & 7 \\
\hline Sajjad & 1 & 7 & 6 \\
\hline Shafique & 3 & 6 & 3 \\
\hline Naseer & 2 & 9 & 7 \\
\hline Wagas & 4 & 8 & 4 \\
\hline Younas & 3 & 10 & 7 \\
\hline Atif & 5 & 3 & -2 \\
\hline TOTAL MARKS & 65 & 224 & \\
\hline AVERAGE & 2.166666667 & 7.4666666667 & \\
\hline PERCENTAGE & 21.666666667 & 74.666666667 & \\
\hline
\end{tabular}

Post-test result indicates that there is positive achievement in teaching students through demonstrations as the $85 \%$ students secured more marks than pre-test which indicated that demonstration method played its vital role in teaching the students abstract concepts. 


\section{DISCUSSION}

The result of the study indicates that round about $85 \%$ children performed well in post-test after teaching them through demonstration method. They scored overall $75 \%$ in post-test that is $56 \%$ better performance than pre-test which was $21 \%$ only, shows that demonstrations has been proved to be very successful to give the children deep insight and understanding of the abstract concepts. Furthermore, it developed the children interest and made them passionate towards learning process. It made the teaching and learning process easy, simple, playful, interesting, flexible, and the most of all, an effective one. Moreover, Demonstration method developed a very useful and an effective interaction among the teacher and the children. It improved the children in many ways. For instance, it developed level of confidence of the children, made better their vocabulary, pronunciation, grammar, extensive reading, presentation and overall competence. In short, it not only made easy to learn abstract concepts but it also helped the children in improving all other said areas or skills. In this way, the demonstration method is an effective method to teach the children abstract concepts and to improve their other skills as well.

\section{CONCLUSION AND RECOMMENDATION FOR FURTHER RESEARCH}

On the basis of the result, it is observed that demonstration is an effective method to improve the children's' understanding regarding abstract concepts. It enhances their proficiency, competency, receptivity, and confidence. Moreover, it improves the children's vocabulary, grammar and sentence building. Furthermore, it develops habit of reading, intensify the concentration of the children and build an effective interaction among the children and the teacher. Demonstration method motivates the children through interesting and repetitive demonstration of the teacher. The children really enjoy the demonstrations posed by the teacher. In short, overall demonstration method can play a very paramount, a pragmatic and a vital role in teaching and learning process. So, it is dire need to implement the demonstration method to teach younger children effectively especially abstract concepts in which the children undergo difficulties in understanding and perceiving them.

Conjunction is another important concept regarding grammar. It is a pragmatic concepts pertaining to sentence building. Unfortunately, most of the teachers cannot convey the concept of conjunction to the students appropriately. They only describe them and the students cannot get them. These concepts also demand certain demonstration to understand. This study directs the researchers to implement the demonstration method to teach conjunction to the younger children.

\section{REFERENCES}

[1] James Nisbet (1949) Demonstration as a teaching technique, with special reference to the teaching of bakery and confectionery, The Vocational Aspect of Education, 1:3, 259-262, DOI: $10.1080 / 03057874980000161$

[2] K. Giridharan \& R. Raju (2016) Impact of Teaching Strategies: Demonstration and Lecture Strategies and Impact of Teacher Effect on Academic Achievement in Engineering Education, International Journal of Educational Sciences, 14:3, 174-186, DOI: $10.1080 / 09751122.2016 .11890491$

[3] Kenneth H. Hoover (1958) Teaching Methods of Teaching by Demonstration and Application, The Clearing House: A Journal of Educational Strategies, Issues and Ideas, 33:2, 90-91, DOI: $10.1080 / 00098655.1958 .11476519$ 
[4] Mcleod, Saul (2018). Jean Piaget' Theory of Cognitive Development.

[5] Piaget, J. (1952). The origins of intelligence in children. New York: International Universities Press.

[6] Thahir Andi, Mawarni Anisa \& Palupi Ratna.(2019). The effectiveness of Demonstration method assisting multiplication board tools for understading mathematical concept in Bandar Lampung: Journal of Education gifted young scientists, 7(2), 353-362.

\section{APpendix A}

Tick the Appropriate Answer.

1.The story "A bear and two friends" is about:
a. Honesty
b. Trustworthiness
c. Truthfulness.
d. Kindness

2.The story "an axe and the angel" tell us about:
a. Honesty
b. Trustworthiness
c. Truthfulness.
d. Kindness

3.Moral lesson of the story "The Truthful" is:
a. Honesty
b. Trustworthiness
c. Truthfulness.
d. Kindness

4.Abstract word "Honesty" means:
a. To behave good to others
b. Avoid stealing others things
c. Keep others thing save and sound
--d. None

5.The word "Trustworthiness" means:
a. Avoid people to misguide them
b. Tell a lie
c. Speak the truth.
d. Have a strong faith on one's self

6.The word "kindness" stands for:
a. Behave bad.
b. behave good c. behave normal. b. Behave abnormal

7.

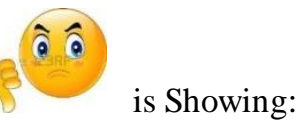

a. Love

b. Hatred

c. anger

d. Kindness

8.

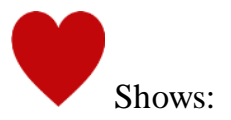
a. Love
b. Hatred
c .anger.
d. Kindness

9.

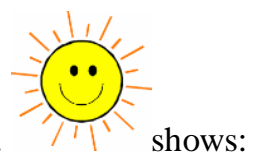
a. Happiness.
b. Sadness
c. Love
d. Hatred 
International Journal of Education (IJE) Vol.8, No.2, June 2020

10. is showing:
a. Happiness
b. Sadness
c. Love d. Hatred

\section{AUTHOR}

The author is an English Teacher in PSED (Punjab School Education Department), Pakistan. He has been serving as a teacher since 2013. He earned his BS (HONS) in English Language and Literature. He also has done his M.phil applied linguistics and Bachelor of Education. He is a well-competent individual. He has been the part of curriculum department in a well-reputed organization, named Minhaj Education Society for three years where he developed an English series for the children up to grade-5. He is well aware of the children psychology. He has very profound concerns with the early childhood education and struggled hard to contribute for the young children.

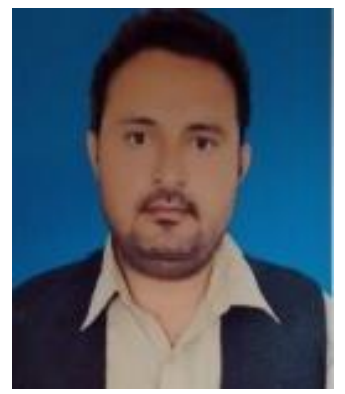

